\title{
Research methodology in global strategy research
}

Article

Accepted Version

Cuervo-Cazurra, A., Mudambi, R., Pedersen, T. and Piscitello, L. (2017) Research methodology in global strategy research. Global Strategy Journal, 7 (3). pp. 233-240. ISSN 2042-5805 doi: https://doi.org/10.1002/gsj.1164 Available at https://centaur.reading.ac.uk/84151/

It is advisable to refer to the publisher's version if you intend to cite from the work. See Guidance on citing.

To link to this article DOI: http://dx.doi.org/10.1002/gsj.1164

Publisher: Wiley for the Strategic Management Society

All outputs in CentAUR are protected by Intellectual Property Rights law, including copyright law. Copyright and IPR is retained by the creators or other copyright holders. Terms and conditions for use of this material are defined in the End User Agreement.

\section{www.reading.ac.uk/centaur}

\section{CentAUR}

Central Archive at the University of Reading

Reading's research outputs online 


\title{
RESEARCH METHODOLOGY IN GLOBAL STRATEGY RESEARCH
}

\author{
Alvaro CUERVO-CAZURRA, Northeastern University \\ Ram MUDAMBI, Temple University \\ Torben PEDERSEN, Bocconi University \\ Lucia PISCITELLO, Politecnico di Milano
}

\begin{abstract}
Managerial abstract: We review advances in research methodology used in global strategy research and provide suggestions for academic studies on how to improve their analyses and arguments. Methodological advances in the extraction of information and in the analysis of datasets have helped deal with challenges that bedeviled earlier studies and resulted in conflicting findings, helping researchers'. These advances have provided researchers with the ability to obtain valid, unbiased results with clear and relevant managerial implications. These methodological advances need to be considered as tools that complement theoretical arguments and well-explained logics and mechanisms so that researchers can provide better and more relevant recommendations to managers designing the global strategies of their organizations.
\end{abstract}

Academic abstract: We review advances in research methodology used in global strategy research and provide suggestions on how researchers can improve their analyses and arguments. Methodological advances in the extraction of information such as computer-aided text analysis and in the analysis of datasets such as differences-in-differences and propensity score matching have helped deal with challenges(e.g. endogeneity and causality) that bedeviled earlier studies and resulted in conflicting findings. These methodological advances need to be considered as tools that complement theoretical arguments and well-explained logics and mechanisms so that 
researchers can provide better and more relevant recommendations to managers designing the global strategies of their organizations.

Keywords: research methods, theory, global strategy, endogeneity, causality 


\section{INTRODUCTION}

Global strategy, in particular, and management, in general, have benefitted tremendously from recent advances in research methodology, i.e., the general research strategy that outlines the way in which research is to be undertaken and identifies the methods to be used in it. The methods define the means and modes of data collection, and which models and statistical techniques to apply. The advances in methods have been generated in the disciplines and introduced in the management field via innovative research articles. However, to facilitate a wider dissemination of these new techniques, a special issue that focuses on these advances in methodology is useful. By highlighting the methods and explaining in detail how to use them in practice with an application to some well-known debates in global strategy, the special issue serves as a loudspeaker of the benefits of using the methods.

This special issue on methodology builds on the tradition at Global Strategy Journal of publishing research platform articles that facilitate the conversation on key themes in global strategy research (Tallman and Pedersen, 2012). More specifically, this issue focuses on methodology articles that outline best practice of different methodologies with a critical assessment of their applicability in addressing issues that are germane to global strategy scholars. As such, we believe this issue will help the research community develop more appropriate knowledge and norms around the use and interpretation of findings. However, we do not believe that editors are the final judges of what is "best practice" and enforcers of strict rules. With this issue of the journal we just want to open up for a conversation on the practice of how to apply advanced techniques that are increasingly being used in global strategy research. The goal is that scholars in our profession develop strong norms of appropriate methodological knowledge and practice. It is our hope that we can contribute to pushing the conversation in this direction with this special issue of the journal. 
The four articles included in the special issue scrutinize very different research methodologies, spanning from the application of Dahl's technique to account for endogeneity in location decisions in foreign markets (Wu et al., 2017), to using Computer-Aided Text Analysis (CATA) on the concept of a global mindset (Belderbos et. al, 2017), to using propensity score matching and differences-in-differences in the analysis of the relationship between internationalization and performance (Chang and Chung, 2017) to the study of complementary and substitution in the analysis of the relationships between internationalization and diversification (Bowen and Sleuwagen, 2017). The logics of the different techniques are outlined and scrutinized, while the critical procedures of the techniques are illustrated on actual research questions in global strategy. The focus is on unfolding the statistical techniques themselves and, as such, the illustrations mainly serve as the context for demonstrating how to apply the best practice of these methods. Each of the four articles provides significant suggestions for best practice, which are highlighted in the following paragraphs

\section{THE RELATIONSHIP BETWEEN INTERNATIONAL DIVERSIFICATION AND PRODUCT DIVERSIFICATION}

The study of firm diversification dates back more to the early studies by Rumelt (1982), Montgomery (1982) and others. Much of this work in strategic management built on the foundations laid in industrial organization economics (IO) (e.g., Caves, 1980). Neoclassical IO economists were mainly interested in the effect of market structure on social welfare. Hence their objective was to use theory to guide the development of welfare maximizing policies. Since competition and antitrust policies were implemented, in the main, within countries, this body of literature focused almost exclusively on product line diversification, i.e., diversification in product space. 
Geography is the complementary space for firm diversification and the analysis of this dimension was undertaken within the international business literature. Early work in this literature stream built on work in finance where internationalization was examined as a means of portfolio diversification (e.g., Levy and Samat, 1970). Rugman (1979) was among the first to study this and in the spirit of this research stream, concluded that international diversification could reduce firm risk.

These two complementary literature streams remained largely disconnected till the pioneering work by scholars in the newly emerging field of global business strategy in the 1990s. These scholars recognized that product line and geography are the two main dimensions of firm diversification. Tallman and $\mathrm{Li}(1996)$ studied the two dimensions together in terms of their effects on firm performance, concluding that the strongest effects appeared to emanate from the product line. Similarly, Hitt et al. (1997) concluded that product diversification reinforces the positive and buffers the negative effects of international diversification. However, these studies treated product line and geographic diversification as independent explanatory variables within a single equation of firm performance. As noted by Bowen and Sleuwagen (2017), this estimation approach carries the underlying assumption that product line diversification and international diversification are independent, uncorrelated decisions.

A more general view would recognize that overall firm strategy encompasses both these dimensions of firm diversification and that each is at least contingent on the other. Hence, proper analysis requires examining both decisions simultaneously (Mudambi and Mudambi, 2002; Cantwell and Piscitello, 2000). Bowen and Sleuwagen (2017) take the approach or assessing whether the two strategies are substitutes or complements. This is an empirically sound and academically valuable exercise. However, it is important to recognize that it is one approach within the overall class of models that recognize the interdependence of the two strategies. 
Several other approaches exist, and these provide a rich field for future research. One alternative approach would be to assess the sequential dynamics of these decisions. In a world where virtually all firms are international from a very young age, it would be interesting to examine whether one of these dimensions necessarily precedes the other - and the contextual factors attendant on the decisions. In other words, it is possible certain industry and market configurations place a great emphasis on early product line diversification, while others place a premium on geographical diversification.

A second alternative approach would be to explore the nuances within each these broad strategies to examine if the overall relationships are correctly specified. For instance, the specifics of geographical diversification strategies involve entry mode decisions. These often differ depending on whether the entry is in the firm's main line of business or a diversification away from its main product line (Mudambi and Mudambi, 2002). The investor's local experience is another contingency, as noted by Hennart and Park (1993): experienced and inexperienced investors systematically prefer different entry modes. Further, foreign and domestic investors have differing strategies when it comes to making investment decisions (Coombs et al., 2006).

These are just a few of potential avenues for future research. The work of Bowen and Sleuwagen (2017) represents an excellent step along a path toward better analysis of global strategy. However, it is important to recognize the broader aspects of the open research questions and to anchor them in extant global strategy research.

\section{QUASI-EXPERIMENTS IN GLOBAL STRATEGY RESEARCH}

As Chang and Chung (2017) note, it is rare in global strategy research to be able to undertake experiments in which one group of subjects is subjected to a treatment and their behavior or outcomes are then compared to subjects in a control group. This is somewhat surprising for researchers in the natural sciences in which experimentation is a common practice because it 
facilitates the identification of causality and the replication of findings by other researchers, thus following the traditional scientific method underpinning much of our recent advances. However, in management in general and global strategy, in particular, conducting experiments is unusual. In social sciences, in contrast to natural sciences, there are additional ethical considerations one needs to take into account when subjecting individuals in firms to a treatment and others not; not only the treated individuals but also the individuals in the control group may react to being part of the experiment (as the Hawthorne experiment discovered in which just being observed by researchers altered the behavior of the subjects); the collection of data on behavior has its particular measurement challenges as individuals may not be truthful in their responses (as the differences between stated and observed hand washing after using the restroom illustrate, Harris Interactive, 2010); and even the prior attitudes toward the topic change the way in which the same data is analyzed and the findings are reported (as the analysis of the crowdsourcing of data analysis of discrimination in soccer reflects, Silberzahn and Uhlmann, 2015).

The use of experiments in social sciences is increasing, with studies in psychology commonly using students assigned to different tasks to analyze the differences between the treated and control groups, and studies in development economics starting to provide individuals or villages with some support and others not and then studying differences between the treated and controlled group. This approach, even if costly in terms of money and time, may not be feasible in global strategy studies, however. In global strategy, the units of analysis are not individuals or entrepreneurs but very large and complex organizations with operations in multiple locations. This creates a level of heterogeneity that limits the ability of the researcher to claim that the companies assigned to different groups are comparable and that the treatment has an effect on the firm. Given the multitude of individuals involved in the firm and the large diversity of operations in different parts of the world, a treatment may merely affect a few individuals in 
one location and the outcomes of such treatment may not be observable when aggregating the reaction at the level of the global firm.

An alternative to running experiments in global strategy is to take advantage of the existence of quasi-experiments, separating between what we may call theoretical quasiexperiments from natural experiments. In both cases, we may use similar methodological techniques, but the logic behind the comparisons of differences between treatment and control groups differs. In theoretical quasi-experiment, we try to compare how the existence of a particular condition, treatment, makes treated individuals differ from control ones, while in the natural experiment we try to compare how the application of an external treatment results in differences in individuals from would have otherwise happened.

In the case of theoretical quasi-experiments, which Chang and Chung (2017) analyze in detail, we aim to understand how a particular characteristic of a company leads to a different outcome from companies that do not have this particular characteristic. Here we have an internal treatment in the form of particular strategies that firms undertake (exports in their case). The challenge here is to identify control firms that are similar to the treatment firms in all characteristics except for the strategy of interest, which is what the propensity score matching aims to do, with the usual caveats that such technique has in terms of how the control group is identified. We can then compare the differences among groups and start making claims that such characteristics did have a particular influence in comparison to the control group, which is what the differences-in-differences technique addresses. Despite its advances, this method has challenges, including both the methodological limitations discussed by the authors, as well as the challenge that the treatment is not fully exogenous: managers make decisions based on the firm characteristics that the researchers observe, on some characteristic that researchers do not observe, and on the actions of other companies. Nevertheless, these approaches and other 
techniques discussed by Chang and Chung (2017) help reduce the endogeneity that has characterized much prior research.

In the case of natural experiments, we try to understand how an external event has affected the behavior of companies. In this case, we have an exogenous event that may or may not result in the change in the behavior of firms. This requires the comparison of what the companies were doing before the treatment and what the companies were doing after the treatment in comparison to companies that were not affected by the treatment (e.g., CuervoCazurra, 2008; Castellani et al., 2008).) This is the realm of differences-in-differences with several alternative approaches available (Bertrand, Duflo, Mullainathan, 2004). Of course, natural experiments are not free of challenges. It is rare that to find a truly exogenous event. With the exception of unpredictable natural disasters, other events that tend to be considered exogenous such as regulation of political changes may not be fully exogenous: managers may have lobbied for the implementation of particular regulations or free trade agreements, or the election of preferred politicians, and prepared their companies for the potential realization of such events. Despite this, natural experiments can be a good source of insights as they provide an opportunity to establish causality relationships that are driven by changes in firm behavior across time and we encourage researchers to be more cognizant of real events in the world and aim to use these events as natural experiments to better understand strategic decisions.

\section{ENDOGENEITY ISSUES IN MODELING LOCATION DECISIONS}

As stated in the GSJ Vision Statement, the essence of global strategy is an expansive world vision that considers the possibilities of every location as a market and as a source of competitive advantage, both alone and when integrated with the rest of the firm. Location choice is therefore a crucial issue. Traditional studies assume that once the company has decided to set an activity abroad, location choice concerns the specific foreign region/country/area among a wider set of 
regions/countries/areas, and the models normally focus on the very last stage of this decision process, i.e. conditionally on several previous choices (like motivations and/or entry mode) companies select those locations that allow them to maximize their profits ${ }^{1}$. Thus, conditional logit (CL) models, traditionally employed to model location choices, assume that companies select among several alternatives, and no correlation exists between alternatives. In other words, all pairs of alternatives are equally dissimilar (Hensher et al., 2005). Alternatively, nested logit (NL) models consider all the alternatives in a given nest $\mathrm{k}$ as perfectly correlated (and therefore equally appealing to the investing companies), and all the nests are equally dissimilar (but not within the nests $)^{2}$.

However, modeling location choice implies assumptions about the decision sequence. In fact, when considering the sequence of decision stages, firms have to make choices about going abroad or remaining at home, about which foreign country, about the entry mode (export, FDI, JVs), and then, once the first decision stage has been set, companies make more detailed choices about the location. As some unobserved factors may influence not only the location choice but also the first decision, endogeneity may actually be an issue. In fact, the need to correct for selection arises from the fact that certain decisions (like the agglomeration, or the distance at which locating the new plant from other existing plants, infrastructures, etc) are the outcome of a previous location decision (e.g. the selection of a given country, region, area).

For this reason, location decisions have been more recently modeled through two-stage models. Namely, as established approaches deal mainly with problems characterized by binaryfirst stage models (where companies select first, e.g. whether to go international or not, whether to enter through greenfield or M\&A, whether to go with a partner or alone), standard two-stage models à la Heckman have been largely and satisfactorily adopted.

\footnotetext{
${ }^{1}$ On the relationship between the decision to internationalize and the potential 'sequential' decision where to locate Belderbos and Sleuwaegen (2005) estimate a nested logit model to address these decisions simultaneously.

${ }^{2}$ Among the same category of location choice models we can add the Poisson model that, under certain conditions, return the same coefficients as the conditional logit (for a discussion on that, see Schmidheiny and Brulhart, 2009).
} 
Within this context, the article by Wu et al. (2017) highlights, once more, the need of considering endogeneity in location choice models. Specifically, with reference to the agglomeration issue investigated in the article, "we do not know whether observed patterns of foreign entrant agglomeration in a host country are driven by country selection. It could be that multinational firms choose countries precisely because they expect to collocate with local firms, thereby conflating country selection with agglomeration".

This article highlights that whenever the first stage is a multiple choice (namely, the choice among several foreign countries), the approach suggested by Dahl (2002) seems to provide the more affordable (in terms of computational effort) and reliable alternative especially when the number of observations is low, and the number of alternative choices in the first-stage decision, as well as the number of independent variables, is high ${ }^{3}$. Importantly, the authors provide a useful decision tree to guide the researcher towards the choice of the most appropriate selection model (Figure 1), illustrate pros and cons of the several alternatives traditionally adopted in the empirical literature, and report the Stata code (Table 7) for implementing in Dahl's correction methodology.

Additionally, this article suggests a rather interesting model for testing another increasingly considered issue in global strategy and strategic management, i.e. agglomeration. In fact, by defining agglomeration as a geographic location with certain characteristics (i.e. at least five/ten/fifteen neighboring plants that are located within a 60/100/200 mile radius of each other), the company's agglomerative behavior may be modeled by a dummy variable taking value 1 if the new plant is located within the agglomeration (and zero otherwise). Although that requires an a priori definition of agglomeration based on a given threshold of geographical proximity ${ }^{4}$, it has

\footnotetext{
${ }^{3}$ For a recent discussion on the need to account for endogeneity issues associated to location choice, see also Branikas et al. (2017).

${ }^{4}$ In fact, one could instead allow for the fact that companies' perceptions might be highly heterogeneous, and that distance may assume different meanings depending on: (1) the aim of the relationships; (2) the industry considered (in services, geographical proximity is less relevant than in manufacturing sectors, as the former benefit from temporary proximity obtained through organizational structures characterized by high mobility of the labor force); and (3) the companies' experiences and sense of place (see Piscitello 2011).
} 
nonetheless the advantage to allow the estimation of a binary model in the second stage (instead of a conditional logit where the company selects among several alternative locations that may present agglomeration or not).

We believe this article also allows us to highlight that further methodological efforts are needed when modeling (or replicating existing studies on) companies' location choice in foreign countries, namely:

(1) Choices of sub-national areas (on which IB has started looking with renewed attention) may be influenced by the previous choice of the region/country/macro-area. Thus, companies' location choices should be modeled as conditional on the previous selection. In fact, few studies started to adopt multi-level models that allow controlling for confounding effects at one level while testing hypotheses at others (e.g., Basile et al., 2008; Peterson et al., 2012). This has some consequences on the theoretical interpretation of the role of location-specific variables, e.g. agglomeration, co-location, institutions.

(2) Ranking of choices. The set of alternative locations to be included in the company's choice set is a delicate issue. In fact, most of the studies include only those alternatives that did receive at least one choice (in a given period), thus excluding a priori all the others that have never been selected (in the period considered). Location studies might instead consider all the possible alternatives, even allowing for a (possibly firm-specific) ranking of the potential set of choices.

(3) The need of considering heterogeneity: the first possibility is to include interactions between the companies' characteristics and the locations' characteristics. Location choice literature has already shown that these pairwise interaction terms play a critical role in explaining location preferences (e.g., Shaver and Flyer, 2000; Alcacer and Chung, 2006) as the same location-specific characteristics may actually enter differently in each company's utility function. Along with this line, although computationally more complex, random coefficient 
models (e.g., Alcacer et al., 2013) that consider coefficients $\beta$ i to vary with the i-th company's characteristics, would allow researchers to identify the idiosyncratic marginal effect of any explanatory variable for a specific firm.

\section{COMPUTER-AIDED TEXT ANALYSIS IN GLOBAL STRATEGY RESEARCH}

Content analysis or Computer-Aided Text Analysis (CATA) is a fundamental and widely applied research method in other areas of the humanities and social sciences; however, with this article, we will display the potential of this technique and provide direction for global strategy researchers interested in using CATA.

CATA is about the examination and systematic categorization of written texts. With the expansion of large textual databases and news archives, CATA offers opportunities to measure latent constructs (or difficult-to-measure constructs) based on secondary data. While the survey is the primary way of measuring latent constructs (like global mindset) CATA offers an alternative way of measuring based on the large textual databases that are now available. As such, CATA is a method to turn huge textual and qualitative information into quantitative variables that can be used in statistical models. In addition, these textual databases are typically broadly available across sectors, firms and years.

The article by Belderbos et al (2017) is outlining the advantages and challenges of Computer-Aided Text Analysis and then displaying the techniques on the concept of Global Mindset. A number of different software packages help to conduct the CATA and the advantages of using this software include saving time, managing huge amounts of qualitative data, and having improved validity and auditability of qualitative research. In this sense, it combines the strengths of computer reliability and human judgment.

The key challenge is to establish the validity checks for the CATA indicators, which includes sampling validity, content validity, discriminant validity, predictive validity and external 
validity. As highlighted, in particular, the three first types of validity are crucial for the validity of the CATA indicators and each of the different types of validation is detailed in the article (Belderbos et al, 2017.).

The applied examples of determining the global mindset of 180 firms in technologyintensive industries might serve as the best illustration of the technique. The first step was to use human judgment in creating the initial list of keywords (based on deductive as well as inductive methods). The second step was identifying a valid sample for the analysis (in this case 129,413 articles in LexisNexis that listed the name of the firm in the headlines). The third step is the key as it establishes the content validity i.e. the accuracy of the individual keywords used to create the construct. This involves human judgment as well as clear decision rules (e.g. on the occurrence of keywords).

When the content validity is established then it can be examined whether the construct is distinct from or partially overlapping with other constructs. Finally, the predictive validity can be tested by assessing whether the empirical results are in accordance with the established literature (in this case, whether global mindset is related to positive firm performance).

This technique involves a sophisticated interaction between the computer and the researcher, where the CATA can help to organize, manage and analyze huge amounts of information, but it is not a substitute for expert human judgment in many phases of the analysis. As highlighted by Belderbos et al. (2017) there is still a lot of discretion that a researcher has to exercise to obtain valid constructs. Therefore, researchers should clearly specify these judgment decisions e.g. the decision rules to classify articles, the level of satisfactory accuracy of the construct etc.

\section{CONCLUSIONS}


The advances in methodology discussed in Belderbos et al. (2017), Bowen and Sleuwagen (2017), Chang and Chung (2017), Wu et al. (2017) have enabled us to address some of the fundamental issues of attribution and endogeneity that have plagued previous studies. Nevertheless, we need to not to forget that no matter how sophisticated econometric techniques are, these are not a substitute for a well thought out and sophisticated explanation of the relationships. The computer does not impose the selection of the dependent variable, independent variables of interest and controls; authors do. This requires not just a careful selection, but also an explanation of why those are the relevant variables to analyze and why the relationships analyzed and findings are relevant for managers. This is an area in which in addition to theoretical advances, good case studies and conversations with managers can help the researchers make sense of the complex relationships analyzed.

Theory and managerial intuitions are not to be neglected as the drivers of the econometric analyses. Especially in the field of global strategy in which the subjects studied are large complex organizations with a myriad of individuals and multiple operations across locations, selecting the right variables can make a large difference. Research on complex organizations suffers from aggregation problems in time, space and unit, with studies assuming that the right unit of time is the year when manager are actually making and adjusting decisions continuously and the annual accounts or observations at the end of the fiscal year are merely a snapshot of a process; studies assuming that the location of study is the operations of the firm in one country, be it the headquarters or the subsidiaries in particular countries, without taking into account that such subsidiaries are located in particular cities and regions within countries and compete and operate locally and not just nationally or internationally; and studies assuming that the unit of analysis is the multinational or the subsidiary and not taking into account the variety of operations within the multinational or the diversity and interrelatedness of activities across subsidiaries. Thus, selecting different time periods, specific locations or particular activities can alter the analyses and 
conclusions drawn from them. This is not something that econometric techniques do; it is something that researchers do informed by theory and managerial practice.

Assumptions on the context of analysis and the ability to generalize also need to be more explicit. It used to be the case that many scholars assumed that US firms were the standard firms to analyze and from which one could draw theoretical insights and that analyses of firm behavior in other countries were done to replicate, compare and contrast their experience against the lessons drawn from US firms. The appearance of multinationals from emerging economies challenged this implicit assumption of generalization from advanced to emerging market firms given the large differences in country context, but apparently at the expense of building another assumption: that the lessons drawn from the study of Chinese firms serve as the basis for generalization to all emerging economies. Both countries, the US and China, are exceptional countries in their economic and political dimensions that require extra care on the ability to generalize to other contexts. The influence of context on firm strategy is at the core of global strategy and drives the mission of Global Strategy Journal. Studies can benefit from going deeper in the influence of the context to provide more relevant recommendations for managers even if such recommendations are not generalizable to all firms in all locations at all times.

No matter how sophisticated the analyses are, it is the researcher the one who, informed by theory and managerial practice, selected to do the particular study and who is in charge of explaining why such study is relevant for the advancement of science and for the betterment of managerial decisions. A well thought out argument and strong theoretical explanations go hand in hand with a sophisticated econometric methodology.

\section{REFERENCES}

Alcácer, J., Chung W. 2007. Location strategies and knowledge spillovers. Management Science 53(5): 760-776. 
Alcácer J., Chung W., Hawk A., Pacheco de Almeida G. 2013. Applying random coefficient models to strategy research: Testing for firm heterogeneity, predicting firm-specific coefficients, and estimating strategy trade-offs. Harvard Business School Working Paper 14-022.

Basile R., Castellani D., Zanfei A. 2008. Location choices of multinational firms in Europe: The role of EU cohesion policy, Journal of International Economics 74: 328-340.

Belderbos R., Grabowska M., Leten B., Kelchtermans S., Ugur N. 2017. On the Use of Computer-Aided Text Analysis in International Business Research. Global Strategy Journal, 7(3): this issue.

Belderbos, R., Sleuwaegen, L. 2005. Competitive Drivers and International Plant Configuration Strategies: A Product Level Test. Strategic Management Journal, 26 (6): 577-593.

Bertrand, M., Duflo, E., Mullainathan, S. 2004. How much should we trust differences-indifferences estimates? Quarterly Journal of Economics, 119 (1): 249-275.

Bowen H. P., Sleuwagen, L. 2017. Are international and product diversification substitutes or complements? Theoretical and empirical perspectives. Global Strategy Journal, 7(3): this issue.

Branikas I., Hong H., Xu J. 2017. Location choice, portfolio choice. NBER Working Paper 23040.

Cantwell J.A., Piscitello L., “Accumulating Technological Competence - Its Changing Impact on Corporate Diversification and Internationalisation", 2000, Industrial and Corporate Change, vol. 9(1): 21-51.

Castellani D., Mariotti I., Piscitello L.,2008. The impact of outward investments on parent company's employment and skill composition. Evidence from the Italian case, Structural Change and Economic Dynamics, 19: 81-94. 
Chang S-J., Chung J. 2017. A quasi-experimental approach to the multinationality-performance relationship: An application to learning-by-exporting Global Strategy Journal, 7(3): this issue.

Coombs J., Mudambi R., Deeds D.L. 2006. An examination of the investments in U.S. biotechnology firms by foreign and domestic partners. Journal of Business Venturing, 21(4): 405-428.

Cuervo-Cazurra, A. 2008. The effectiveness of laws against bribery abroad. Journal of International Business Studies, 39(4): 634-651.

Dahl G.B. 2002. Mobility and the return to education: Testing a Roy model with multiple market, Econometrica 70(6): 2367-2420.

Harris Interactive. 2010. Survey of hand washing behavior (trended): Prepared for the American Microbiology Society and the American Cleaning Institute. Retrieved from http://www.cleaninginstitute.org/assets/1/AssetManager/2010\%20Hand\%20Washing\%20 Findings.pdf. Accessed May 17, 2017

Hennart J., Park Y-R. 1993. Greenfield vs. acquisition: the strategy of Japanese investors in the United States. Management Science, 39(9): 1054-1070.

Hensher D.A., Rose J.M., Greene W.H. 2005. Applied Discrete Choice Analysis. Cambridge University Press.

Hitt., M., Hoskission, R., Kim, H. 1997. International diversification: effects on innovation and firm performance in product-diversified firms. Academy of Management Journal, 40(4): 767-798.

Levy H., Samat M. 1970. International diversification of investment portfolios. American Economic Review, 60(4): 668-675.

Montgomery, C. 1982. The measurement of firm diversification: some new empirical evidence. Academy of Management Journal, 25(2): 299-307. 
Mudambi R., Mudambi S. 2002. Diversification and market entry choices in the context of foreign direct investment. International Business Review, 11(1): 35-55.

Peterson M.F., Arregle J.-L., Martin X. 2012. Multilevel models in international business research, Journal of International Business Studies, 43: 451-457.

Piscitello L. 2001. Strategy, location, and the conceptual metamorphosis of the MNE, Global Strategy Journal, 1(1-2): 127-131.

Rugman, A. 1979. International diversification and multinational enterprise. Lexington Books: Lexington MA.

Rumelt, R.P. 1982. Diversification strategy and profitability. Strategic Management Journal, 3(4): 359-369.

Shaver JM, Flyer F. 2000. Agglomeration economies, firm heterogeneity, and foreign direct investment in the United States. Strategic Management Journal 21(12): 1175-1193.

Silberzahn, R. \& Uhlmann, E. L. 2015. Crowdsourced research: Many hands make tight work. Nature, October 7. http://www.nature.com/news/crowdsourced-research-many-handsmake-tight-work-1.18508

Tallman S., Li J. 1996. Effects of international diversity and product diversity on the performance of multinational firms. Academy of Management Journal, 39(1): 179-196.

Tallman, S. and Pedersen, T. 2012. Point-Counterpoint on Multinationalization and Performance. Global Strategy Journal, 2: 313-317.

Wu Z., Salomon R., Martin X. 2017. Complex Strategic Choices: A New Approach with an Application to Adaptive Agglomeration Strategies Among Foreign Entrants Global Strategy Journal, 7(3): this issue. 